\title{
Management of Hypertension in High-Risk Ethnic Minority with Heart Failure
}

\author{
M. Demede, ${ }^{1,2}$ A. Pandey, ${ }^{1,2}$ L. Innasimuthu, ${ }^{1}$ G. Jean-Louis, ${ }^{1,3}$ \\ S. I. McFarlane, ${ }^{4}$ and G. Ogedegbe ${ }^{5}$ \\ ${ }^{1}$ Division of Cardiovascular Medicine, Department of Medicine SUNY Downstate Medical Center, 450 Clarkson Avenue, \\ Brooklyn, NY 11203-2098, USA \\ ${ }^{2}$ Brooklyn Health Disparities Center, Department of Medicine, SUNY Downstate Medical Center, NY 11203-2098, USA \\ ${ }^{3}$ Sleep Disorders Center, Department of Medicine, SUNY Downstate Medical Center, 450 Clarkson Avenue, Brooklyn, \\ NY 11203-2098, USA \\ ${ }^{4}$ Division of Endocrinology, Department of Medicine SUNY Downstate Medical Center, 450 Clarkson Avenue, Brooklyn, \\ NY 11203-2098, USA \\ ${ }^{5}$ Center for Healthful Behavior Change, Division of Internal Medicine, NYU Medical Center, New York, NY, USA
}

Correspondence should be addressed to G. Jean-Louis, jeanlouisg@yahoo.com

Received 19 February 2011; Accepted 28 March 2011

Academic Editor: Adam T. Whaley-Connell

Copyright ( 2011 M. Demede et al. This is an open access article distributed under the Creative Commons Attribution License, which permits unrestricted use, distribution, and reproduction in any medium, provided the original work is properly cited.

Hypertension (HTN) is the most common co-morbidity in the world, and its sequelae, heart failure (HF) is one of most common causes of mortality and morbidity in the world. Current understanding of pathophysiology and management of HTN in HF is mainly based on studies, which have mainly included whites. Among racial groups, African-American adults have the highest rates $(44 \%)$ of hypertension in the world and are more resistant to treatment. There is an emerging consensus on the significance of racial disparities in the pathophysiology and treatment options of hypertension and heart failure. However, African Americans had been underrepresented in all the trials until the initiation of the A-HEFT trial. Since the recognition of obstructive sleep apnea (OSA) as an important medical condition, large clinical trials have shown benefits of OSA treatment among patients with HTN and HF. This paper focuses on the pathophysiology, causes of secondary hypertension, and treatment of hypertension among African-American patients with heart failure. There is increasing need for randomized clinical trials testing innovative treatment options for African-American patients.

\section{Introduction}

Hypertension (HTN) is the most common comorbidity in the world with significant public health implications $[1,2]$. The overall U.S. prevalence of hypertension among adults ages $\geq 18$ years in $2005-2008$ was $30.9 \%$ and was highest among persons ages $\geq 65$ years $(69.7 \%)$ [3] and nonHispanic blacks (44\%) [4]. The American Heart Association estimates that the incurred costs of hypertension are more than $\$ 93.5$ billion per year, and that cardiovascular disease and stroke for which HTN is the predominant risk factor, account for $17 \%$ of the total annual health expenditures in the United States [5].

Hypertension and its sequelae, heart failure (HF) [6], are a progressive disease. Evidence shows that less than half of patients with heart failure survive five years (after diagnosis), and less than a quarter of them live ten years after their initial diagnosis [7]. The incidence is about 550,000 each year in the United States. Framingham Heart Study showed that hypertensive patients were more likely to develop heart failure (142 cases of HF detected during the first 16 years of followup) than those who were normotensive [8]. The lifetime risk for development of HF among people with blood pressure (BP) $>160 / 90 \mathrm{~mm} \mathrm{Hg}$ is double that of those with $\mathrm{BP}<140 / 90 \mathrm{~mm} \mathrm{Hg}$. Heart failure in comparison to the most prevalent gender malignancies (bowel cancer in men and breast cancer in women), was associated with worse long-term survival [9]. In addition to poor prognosis, the socioeconomic burden is enormous. Over a million hospitalizations, contributing to more than 250,000 deaths [4], and escalating billions of dollars in health care expenditure is the norm [10]. 
The disastrous duo, HTN and HF, should be recognized, and a tailored focus on management in special populations, high-risk ethnic minority groups especially blacks who are disproportionately burdened should be developed. Among racial groups, African-American adults have the highest rates (44\%) of hypertension in the world [4] and are more resistant [11] to treatment. In particular, black women have the highest prevalence [4] and the lowest blood pressure control [12]. The relative incidence of $\mathrm{HF}$ is $50 \%$ higher in African Americans, 3\% of whom have HF, compared with $2 \%$ of the general population $[13,14]$. Incident HF is substantially more common among black than nonblack hypertensive patients [15]. The disease occurs at an earlier age, and usually at a more advanced stage [10] along with increased hospitalization [16] and mortality.

Hypertension is one of the most common causes of HF. Other causes of HF include coronary artery disease, valvular heart disease, diabetes, left ventricular hypertrophy and cardiomyopathies. HF can result from systolic, diastolic or combined left ventricular dysfunction [17]. Overt clinical HF resulting from diastolic left ventricular dysfunction may be clinically indistinguishable from that resulting from systolic dysfunction. HF with preserved left ventricular function is observed in $30 \%$ to $50 \%$ of adult cases of HF. Coronary artery disease and myocardial infarction is a principal cause of systolic left ventricular dysfunction followed by hypertension. A variety of neurohormonal systems, especially the reninangiotensin aldosterone and sympathetic nervous systems are activated in response to the left ventricular dysfunction and such activation leads to abnormal ventricular remodeling. The inexorable progression to more severe stages of left ventricular dysfunction can be significantly reduced by effective therapy with neurohormonal blockade including Angiotensin Converting enzyme inhibitors (ACEIs), Beta Blockers (BBs), and aldosterone antagonists [18].

1.1. Pathophysiology. Current understanding of the pathophysiology of HF has revolved around neurohormonal activation $[19,20]$. Evidence suggests that abnormal endothelial function may contribute to abnormal blood pressure responses. This endothelial dysfunction may result from insufficient nitric oxide (NO) secondary to either reduced endothelial production of $\mathrm{NO}$ or to increase $\mathrm{NO}$ inactivation $[17,19,21]$. In HF, a pronounced increase in angiotensin II, with modestly reduced NO is seen among whites. However, African Americans with HF may exhibit greater NO reduction; conversely, angiotensin II might be less elevated among whites.

Important studies are investigating gene variation among the races that may influence the risk of developing hypertension and its complications, such as single nucleotide polymorphisms in the genes encoding for $\beta 1$-adrenergic receptors and a $2 \mathrm{c}$-adrenergic receptors. African Americans who are homozygous for polymorphisms in both the $\beta 1$ adrenergic and a2c-adrenergic receptor genes are at a 10 fold greater risk for heart failure, which is overexpressed in African-Americans [22]. Groups with overexpression of transforming growth factor $\beta-1$ (TGF- $\beta 1$ ), a cytokine involved in cardiac fibrosis and remodeling, vascular and renal disease, production of the vasoconstrictor, endothelin1 , and stimulation of renin release, have a worse prognosis. Other genetic polymorphisms in African Americans that may influence heart failure risk include elevated production of endothelial nitric oxide synthase, aldosterone synthase, and the $\mathrm{G}$ protein $825-\mathrm{T}$ allele [14].

\section{Management}

There are two major approaches to classifying the patient's HF stage or clinical severity. The most common is the New York Heart Association (NYHA) classification, mainly based on functional capacity and subjective level of symptoms severity. This scheme is fluid and its class fluctuates in the same patient depending on their subjective assessment and clinical status. The other approach, adopted by the American College of Cardiology/American Heart Association (ACC/AHA) guidelines, emphasizes disease progression. Classified as stages A, B, C, and D, each of these stages has definable characteristics and recommended interventions. To emphasize the progressive nature of $\mathrm{HF}$ and the need to prevent its development or progression to end-stage disease (stage D) $[18,23]$, this scheme is unidirectional. Patients can only progress toward worsened disease severity.

Current HF guidelines define patients in stage $\mathrm{A}$ as those at increased risk for HF without evidence of structural heart disease or symptoms of HF [18]. Stage A represents a critically important group because many of the risk factors including hypertension can be effectively controlled and by doing so may prevent development of cardiovascular diseases including HF. Patients are in stage B when they present with evidence of structural heart disease but without current or prior symptoms of HF. Stage C is recognized by the presence of structural heart disease and current or prior symptoms of HF. Stage D patients are those who have refractory heart failure requiring frequent hospitalization and specialized interventions. They are symptomatic at rest despite maximally tolerated medical and device therapy.

\section{Treatment of Hypertension in Heart Failure}

Several studies have shown the efficacy of treatment of hypertension in preventing HF [24-27]. Treatment of hypertension reduces the incidence of $\mathrm{HF}$ by about $50 \%$. In recent years, significant advances have been made in increasing awareness, treatment, and control of blood pressure. Several large, randomized clinical trials have shown that specific classes of medication have mortality benefit in patients with heart failure [28-34].

3.1. Treatment Goals. In the most recent guidelines [18] for the diagnosis and management of HF in adults, the American College of Cardiology Foundation (ACCF)/American Heart Association (AHA) recognized the need for specific recommendations for special population. Our review expounds on the specific concerns in Blacks.

3.2. Lifestyle Therapy. Lifestyle modifications have been shown to reduce blood pressure, increase drug efficacy, 
and decrease cardiovascular risk. Long-term primary prevention of hypertension includes weight reduction in overweight/obese individuals. Weight loss intervention was associated with a $21 \%$ reduction in the incidence of hypertension over a 36-month period [35]. Dietary practices, reducing intake of dietary sodium to $<1.5 \mathrm{~g} \mathrm{NaCl}[3,36]$, low potassium, magnesium, and saturated fat intake, increased calcium intake [37], decreased consumption of alcohol, have demonstrated greater BP reduction in blacks [38]. These practices are most successful when reinforced with comprehensive education and counseling [39, 40]. Exercise training, regular aerobic physical activity for at least 30 minutes per day most days [41], has been shown to reduce recurrent cardiac events in patients with LV dysfunction from ischemic heart disease and is recommended under close medical supervision [42]. Culturally cognizant and sensitive modalities should be implemented to help guide improved compliance of therapeutic lifestyle changes (TLC) in special populations $[43,44]$.

3.3. Pharmaceutical Therapy. Despite lifestyle modifications, most patients with hypertension need pharmacologic therapy for better BP control. In the United States, about 44 million patients are on antihypertensive medications [45].

Pharmacological treatment of hypertension before development of structural heart disease or symptoms of HF is mainly based on studies looking at prevention of end-organ damage. Specific classes of medication are recommended for patients in stages B-D that have shown benefit in reducing mortality and number of hospitalizations. The reader should refer to the major guidelines for full treatment recommendations of HF in the general population $[18,23,46]$.

There are multiple large trials for HF therapy including management of HTN. However, ethnic minorities who are at greater risk for developing HF remain underrepresented in most clinical trials. According to a recent paper by Mitchell et al. "Treatment of HF in African Americans-A call to Action", most of the available evidence is based on limited representation of African Americans in these trials or posthoc analysis of limited evidence [46]. These papers once again summarize the available evidence in HF management in African Americans and call for more therapeutic trial focused in these high-risk population. The African American Heart Failure Trial (A-HEFT) was the first heart failure large trial to focus specifically on the African-American population and evidence represented approximately $50 \%$ of all African Americans ever studied in heart failure trials [47]. This is randomized placebo-controlled double blind study of fixed dose isosorbide dinitrate/hydralazine (ISBD/HYD) (Figure 2).

In an effort to summarize efficacy of available treatments, Psaty et al. conducted a meta-analysis of all trials through 2002 [48]. The database included 192,478 patients from 42 trials randomized to 7 treatment strategies including placebo. Low-dose diuretics proved the most effective firstline treatment for preventing cardiovascular disease and mortality including HF. The ALLHAT trial showed that diuretics are as effective as calcium channel blockers or ACEI in preventing cardiovascular disease outcomes including HF.
The ALLHAT study also has suggested that thiazide-diuretic therapy is useful in preventing disease progression [49]. Although, ALLHAT trials and other trials showed diuretics is the first-line of antihypertensive therapy and is still the most commonly prescribed antihypertensive medications, this is challenged by recent studies as published in February JACC and presented in the European Society of HTN meetings. However, the diuretics used in the ALLHAT trials was chlorthalidone a long acting thiazide (shown to effectively lower BP and improve survival), not really the same as hydrochlorothiazide (HCTZ) which is the most commonly prescribed antihypertensive thiazide at a dose of $12.5-25 \mathrm{mg}$. Messerli et al. (St Luke Roosevelt Hospital, New York, NY), published the analysis of 18 trials on HCTZ where the antihypertensive effect of HCTZ at the dose that is most often used-12.5 to $25 \mathrm{mg}$ a day-is consistently inferior to that of most other antihypertensive drug [50]. The other limitation of diuretics as first line therapy in African Americans is not only not adequate but also, has multiple side effects like DM, electrolyte abnormalities and urecemia, to mention a few. However, there is still a role of diuretics in combination with neurohormonal (Renin Angiotensin Aldosterone Axis) blockade and when there is compelling indication. According to the recent consensus statement of the International Society on Hypertension in Blacks (ISHB), chlorthalidone is favored than HCTZ [51]. Furthermore, the ISHB consensus statement reinforces, patient above goal BP (SBP/DBP - 15/10) with (goal BP - < 130/80) end organ damage (HF, LVH, Kidney disease) or without end organ damage (goal $\mathrm{BP}-<135 / 85$ ) should be on at least on combination pharmacotherapy [51].

Use of beta blockers (BB) as treatment for hypertension has come under scrutiny. Lindholm et al. conducted a metaanalysis of 13 trials, which included 105,951 patients showing that atenolol did not improve outcomes in terms of stroke and cardiovascular events [52]. In stage B CHF (NYHA class I), defined by the presence of reduced left ventricular ejection fraction (LVEF) $<40$ percent in otherwise asymptomatic individuals, ACEIs and BBs are recommended. Stage C HF patients (NYHA class II-III) manifest left ventricular dysfunction and overt symptoms; in these individuals, ACEIs and $\mathrm{BBs}$ are also indicated. Aldosterone antagonists also may be of value in these cases [51].

HF is an indication for the use of ACEI. Abundant evidence exists to justify their use with all stages of HF. Patients who are intolerant to ACEIs, ARBs may be used. $\mathrm{BBs}$ are also recommended in HF because of clinical studies demonstrating decreased morbidity and mortality, and improvement in HF symptoms. The reduction of BP with $\mathrm{BBs}$ may be very marginal. Aldosterone antagonists may provide additional benefit in patients with severe left ventricular dysfunction, usually late stage C (NYHA class III-IV). In the Randomized Aldactone Evaluation Study (RALES), low-dose spironolactone (12.5-25 mg daily), when added to standard therapy, decreased mortality by 34 percent [34]. In the Eplerenone Postacute Myocardial Infarction Heart Failure Efficacy and Survival Study (EPHESUS), eplerenone reduced mortality by $15 \%$ in patients following a recent MI with LVEF $<40 \%, 90 \%$ of whom had HF 
symptoms [53]. Patients were excluded who had a serum creatinine of $<2.5 \mathrm{mg} / \mathrm{dL}$ and hyperkalemia.

The V-HEFT I and II are a large-scale trial that compared different vasodilators with placebo and among themselves [25]. V-HEFT I showed, the mortality rate was significantly lower for the total cohort (African Americans and Whites) in ISDN/HYD arm compared to patients treated with Prazosin or placebo added to digitalis and diuretics (Figure 1) [54].

In V-HEFT II, though ISBD/HYD was statistically inferior to enalapril in effect on mortality, patients taking ISBD/HYD experienced similar mortality rate in patients taking ISBD/HYD in V-HEFT-II as those in V-HEFT-I taking ISBD/HYD. Posthoc analysis of V-HEFT I showed ISBD/HYD significantly reduced mortality in African American patients but not in white patients. The reanalysis of $\mathrm{V}$ HEFT II, demonstrated the annual mortality rate African American (12.9) patients receiving ISBD/HYD was $12.9 \%$ compared with $12.8 \%$ for African Americans receiving enalapril. Due to difference in outcomes in African Americans in V-HEFT, the African American Heart Failure Trial (A-HEFT) definitive study was designed. The A-HEFT was terminated earlier than anticipated completion date due to a significant $(43 \%)$ reduction in mortality in patients receiving combination (ISDN/HYD) compared to the placebo arm [44].

Adding the combination of a fixed-dose of ISDN/HYD $(20 \mathrm{mg} / 37.5 \mathrm{mg})$ to a standard medical regimen for $\mathrm{HF}$, including ACEI and BBs, is recommended in order to improve outcomes for patients self-described as African Americans, with NYHA functional class III or IV CHF [47]. Furthermore, genomic evidence from the GRAHF (Genetic Risk Assessment of Heart Failure in African Americans) arm of the African American Heart Failure Trial (A-HEFT) showed that blacks with the more common TT phenotype $(61 \%)$ of the aldosterone synthase gene (CYP11B2) showed greater responsiveness to the combination of isosorbide dinitrate and hydralazine [55].

3.4. Secondary HTN. The vast majority of blacks will have no identified cause for their HTN [56]. Past studies elucidating the pathophysiological mechanisms have shown conflicting information and further investigations exploring the complex relationships and interactions are warranted [57]. There are, however, several secondary forms of HTN in blacks that are prominent and preventable. We will focus on the most common, preventable and treatable secondary form of hypertension, obstructive sleep apnea (OSA) [58].

3.5. Obstructive Sleep Apnea. The prevalence of OSA in hypertensive populations is estimated to range between (30-40\%) [59] and in heart failure at 53\%; apnea-hypopnea index $(\mathrm{AHI}) \geq 10 / \mathrm{h})[60]$. OSA is more common in blacks than whites $[61,62]$. It is an independent risk factor for HTN [63], nondipping of blood pressure and increased BP variability [64] and follows a dose-dependent relationship [65]. A prospective study showed that the odds of developing hypertension over 4-8 years was 2.89 times more likely for participants who had AHI $\geq 15 / \mathrm{h}$ compared to $\mathrm{AHI} \geq 0$, independent of known confounders [66]. Cross-sectional

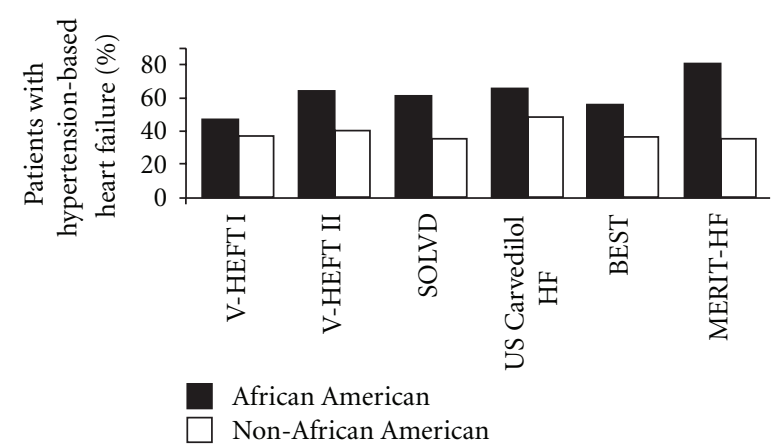

Figure 1: Higher rates of hypertension-based heart failure among African American patients compared to white patients in heart failure trials. V-HEFT: Vasodilator Heart Failure Trial; SOLVD: Studies of Left Ventricular Dysfunction; US Carvedilol: US Carvedilol Heart Failure Trial; BEST: $\beta$-Blocker Evaluation of Survival Trial; MERITheart failure: Metoprolol CR/XL Randomized Intervention Trial in Congestive Heart Failure [14].

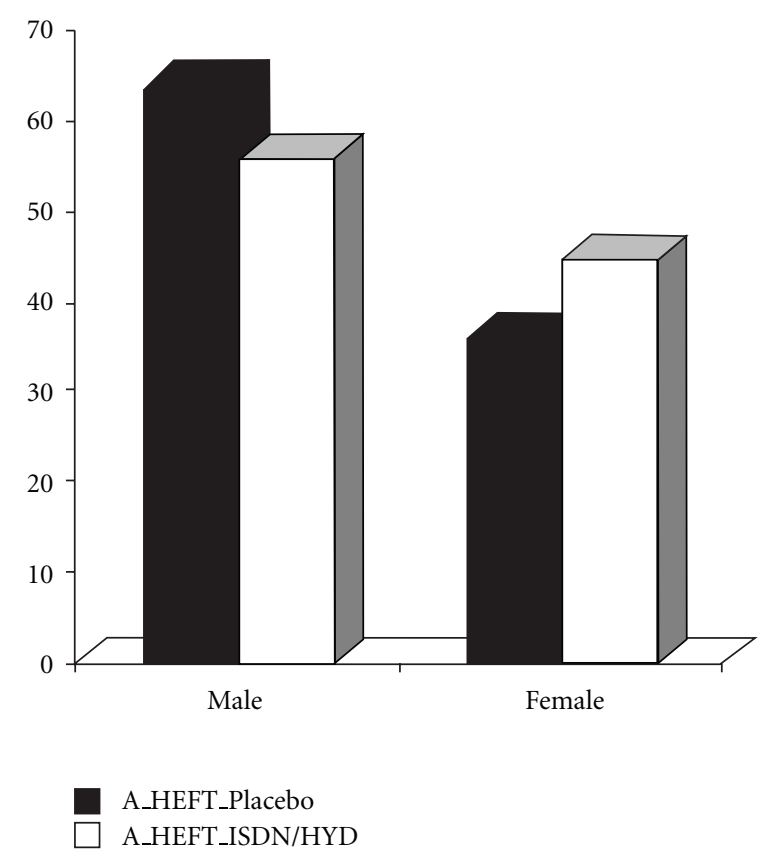

FIGURE 2: A-HEFT \% of black participants in different intervention arms [14].

data has shown 2.38-times increased likelihood of having heart failure in association with OSA, independent of confounders $(n=6424)[67,68]$.

OSA has been shown to act through various mechanisms, independent of blood pressure, in promoting leftventricular (LV) hypertrophy, diastolic [69], and systolic [70] dysfunction, and overt heart failure [71]. These mechanisms include the hemodynamic consequences of repetitive increases in left-ventricular transmutable wall pressure and over time impaired vigil heart rate modulation leading to LV hypertrophy and ventricular remodeling [58]. Additionally, OSA patients without overt heart failure have more impaired diastolic relaxation than those without OSA [72]. Emerging 
evidence illustrates patients with OSA have more active atherosclerotic disease with a greater degree of vessel involvement and more vulnerable plaques than do patients without the disease, resulting in greater cardiovascular burden [73].

The definite treatment for OSA, long-term adherence to Continuous Positive Airway Pressure (CPAP) therapy, has shown to suppress sympathetic activity [74], lower blood pressure [75], reduce right ventricular volume [76], and improve systolic function in patients with HF [77]. Systematic reviews, meta-analyses, and randomized controlled trials have shown statistically significant net reduction in blood pressure with CPAP, especially in patients with increased AHI events [78-83]. A recent 3-year study $(n=340)$ by Durán-Cantolla et al. reported that participants assigned to CPAP therapy for 3 months had mean 24-hour ambulatory blood pressure decreased by $2.1 \mathrm{mmHg}(0.4$ to 3.7$) \mathrm{mmHg}$ $(P=.01)$ for systolic and $1.3(0.2$ to 2.3$) \mathrm{mm} \mathrm{Hg}(P=.02)$ for diastolic blood pressures [84]. Similar evidence from randomized trials showed up to 9\% increase in LVEF [77] and increased quality of life (QOL) and functional capacity among patients treated with 1-3 months of CPAP therapy [85]. Furthermore, among patients with no overt failure, CPAP therapy has been shown to reverse impaired diastolic relaxation [71]. There is a need for further randomized clinical trials with CPAP therapy among high-risk ethnic minorities especially blacks to assess whether treatment of OSA has similar long-term effects and to evaluate the effect on HTN and HF morbidity and mortality.

\section{Recommendations}

Taking into consideration, lifestyle and pharmaceutical interventions, our changing health care community needs to emphasize the essential nature of the patient-provider relationship and establish trust and collaboration. In the past, this has been accomplished through physician, patients, family member, and other caretaker awareness, increased education of both provider and patients, and establishment of community outreach programs [86]. These measures have contributed to an increase in compliance and a reduction in the risk of hospitalizations [23, 87]. We recommend an additional emphasis on the implementation of specialty care in patients with heart failure in collaboration with the primary care provider.

\section{Summary}

The dramatic improvement in the management of HF and hypertension over the last 50 years has allowed us to start to target specific populations and provide more evidence-based treatment that will lead to an improvement in mortality [88]. There are disparities in the prevalence, treatment, and control of hypertension and the incidence and morbidity and mortality of heart failure between blacks, a diverse and heterogeneous population, and whites. The management team needs to take into consideration new evidence and develop tailored strategies for effective treatment, especially for hypertension, one of the main causes of HF and many other cardiovascular complications in African Africans.

\section{Acknowledgment}

This research was supported by funding from the NIH (R25HL105444, R01MD004113, and P20MD005092).

\section{References}

[1] P. M. Kearney, M. Whelton, K. Reynolds, P. Muntner, P. K. Whelton, and J. He, "Global burden of hypertension: analysis of worldwide data," Lancet, vol. 365, no. 9455, pp. 217-223, 2005.

[2] M. Ezzati, A. D. Lopez, A. Rodgers, H. S. Vander, and C. J. L. Murray, "Selected major risk factors and global and regional burden of disease," Lancet, vol. 360, no. 9343, pp. 1347-1360, 2002.

[3] "Vital signs: prevalence, treatment, and control of hypertension-United States, 1999-2002 and 2005-2008," Morbidity and Mortality Weekly Report, vol. 60, no. 4, pp. 103-108, 2011.

[4] V. L. Roger, A. S. Go, D. M. Lloyd-Jones et al., "Heart disease and stroke statistics-2011 update: a report from the American Heart Association," Circulation, vol. 123, no. 4, pp. e18-e19, 2011.

[5] P. A. Heidenreich, J. G. Trogdon, O. A. Khavjou et al., "Forecasting the future of cardiovascular disease in the United States: a policy statement from the American Heart Association," Circulation, vol. 123, no. 8, pp. 933-944, 2011.

[6] D. Levy, M. G. Larson, R. S. Vasan, W. B. Kannel, and K. K. L. Ho, "The progression from hypertension to congestive heart failure," Journal of the American Medical Association, vol. 275, no. 20, pp. 1557-1562, 1996.

[7] M. R. Jonovich and J. D. Bisognano, "Management of hypertension in chronic heart failure," Manual of Heart Failure Management, pp. 1-15, 2009.

[8] W. B. Kannel, W. P. Castelli, P. M. McNamara, P. A. McKee, and M. Feinleib, "Role of blood pressure in the development of congestive heart failure. The Framingham study," New England Journal of Medicine, vol. 287, no. 16, pp. 781-787, 1972.

[9] S. Stewart, K. MacIntyre, D. J. Hole, S. Capewell, and J. J. V. McMurray, "More "malignant" than cancer? Five-year survival following a first admission for heart failure," European Journal of Heart Failure, vol. 3, no. 3, pp. 315-322, 2001.

[10] J. A. Franciosa, K. C. Ferdinand, and C. W. Yancy, "Treatment of heart failure in African Americans: a consensus statement," Congestive Heart Failure, vol. 16, no. 1, pp. 27-38, 2010.

[11] W. C. Cushman, C. E. Ford, P. T. Einhorn et al., "Blood pressure control by drug group in the antihypertensive and lipid-lowering treatment to prevent heart attack trial (ALLHAT)," Journal of Clinical Hypertension, vol. 10, no. 10, pp. 751-760, 2008.

[12] W. C. Cushman, C. E. Ford, J. A. Cutler et al., "Success and predictors of blood pressure control in diverse North American settings: the antihypertensive and lipid-lowering treatment to prevent heart attact trial (ALLHAT)," Journal of Clinical Hypertension, vol. 4, no. 6, pp. 393-404, 2002.

[13] A. V. Chobanian, G. L. Bakris, H. R. Black et al., "The seventh report of the joint national committee on prevention, detection, evaluation, and treatment of high blood pressure: The JNC 7 report," Journal of the American Medical Association, vol. 289, no. 19, pp. 2560-2572, 2003.

[14] C. W. Yancy, "Heart failure in African Americans," American Journal of Cardiology, vol. 96, no. 7, pp. 3i-12i, 2005. 
[15] P. M. Okin, S. E. Kjeldsen, B. Dahlof, and R. B. Devereux, "Racial differences in incident heart failure during antihypertensive therapy," Circadian Cardiovascular Quality Outcomes, vol. 4, no. 2, pp. 157-164, 2011.

[16] L. S. Evangelista, K. Dracup, and L. V. Doering, "Racial differences in treatment-seeking delays among heart failure patients," Journal of Cardiac Failure, vol. 8, no. 6, pp. 381-386, 2002.

[17] J. A. Vita, "Nitric oxide and vascular reactivity in African American patients with hypertension," Journal of Cardiac Failure, vol. 9, no. 5, pp. S199-S204, 2003.

[18] M. Jessup, W. T. Abraham, D. E. Casey et al., "2009 focused update: ACCF/AHA guidelines for the diagnosis and management of heart failure in adults: a report of the American College of Cardiology Foundation/American Heart Association Task Force on practice guidelines: developed in collaboration with the International Society for Heart and Lung Transplantation," Circulation, vol. 119, no. 14, pp. 19772016, 2009.

[19] J. Loscalzo and G. Welch, "Nitric oxide and its role in the cardiovascular system," Progress in Cardiovascular Diseases, vol. 38, no. 2, pp. 87-104, 1995.

[20] M. R. Weir, J. M. Gray, R. Paster, and E. Saunders, “Differing mechanisms of action of angiotensin-converting enzyme inhibition in black and white hypertensive patients," Hypertension, vol. 26, no. 1, pp. 124-130, 1995.

[21] C. Cardillo, C. M. Kilcoyne, R. O. Cannon, and J. A. Panza, "Racial differences in nitric oxide-mediated vasodilator response to mental stress in the forearm circulation," Hypertension, vol. 31, no. 6, pp. 1235-1239, 1998.

[22] K. M. Small, L. E. Wagoner, A. M. Levin, S. L. R. Kardia, and S. B. Liggett, "Synergistic polymorphisms of $\beta$ - and $\alpha$-adrenergic receptors and the risk of congestive heart failure," New England Journal of Medicine, vol. 347, no. 15, pp. 1135-1142, 2002.

[23] S. A. Hunt, W. T. Abraham, M. H. Chin et al., "ACC/AHA 2005 guideline update for the diagnosis and management of chronic heart failure in the adult: a report of the American College of Cardiology/American Heart Association Task Force on Practice Guidelines (Writing Committee to Update the 2001 Guidelines for the Evaluation and Management of Heart Failure): developed in collaboration with the American College of Chest Physicians and the International Society for Heart and Lung Transplantation: endorsed by the Heart Rhythm Society," Circulation., vol. 112, no. 12, pp. e154-e235, 2005.

[24] J. L. Probstfield, "Prevention of stroke by antihypertensive drug treatment in older persons with isolated systolic hypertension: final results of the Systolic Hypertension in the Elderly Program (SHEP)," Journal of the American Medical Association, vol. 265, no. 24, pp. 3255-3264, 1991.

[25] "Effects of treatment on morbidity in hypertension. Results in patients with diastolic blood pressures averaging 115 through $129 \mathrm{~mm}$ Hg," Journal of the American Medical Association, vol. 202, no. 11, pp. 1028-1034, 1967.

[26] "Effects of treatment on morbidity in hypertension-II. Results in patients with diastolic blood pressure averaging 90 through $114 \mathrm{~mm} \mathrm{Hg,"} \mathrm{Journal} \mathrm{of} \mathrm{the} \mathrm{American} \mathrm{Medical}$ Association, vol. 213, no. 7, pp. 1143-1152, 1970.

[27] B. Dahlof, L. H. Lindholm, L. Hansson, B. Schersten, T. Ekbom, and P. O. Wester, "Morbidity and mortality in the Swedish Trial in Old Patients with Hypertension (STOPHypertension)," Lancet, vol. 338, no. 8778, pp. 1281-1285, 1991.
[28] J. N. Cohn, D. G. Archibald, and S. Ziesche, "Effect of vasodilator therapy on mortality in chronic congestive heart failure: results of a Veterans Administration Cooperative Study," New England Journal of Medicine, vol. 314, no. 24, pp. 1547-1552, 1986.

[29] K. Swedberg, U. Idanpaan-Heikkila, and J. Remes, "Effects of enalapril on mortality in severe congestive heart failure. Results of the Cooperative North Scandinavian Enalapril Survival Study (CONSENSUS)," New England Journal of Medicine, vol. 316, no. 23, pp. 1429-1435, 1987.

[30] S. Yusuf, "Effect of enalapril on survival in patients with reduced left ventricular ejection fractions and congestive heart failure," New England Journal of Medicine, vol. 325, no. 5, pp. 293-302, 1991.

[31] M. Packer, M. R. Bristow, J. N. Cohn et al., "The effect of carvedilol on morbidity and mortality in patients with chronic heart failure," New England Journal of Medicine, vol. 334, no. 21, pp. 1349-1355, 1996.

[32] A. Hjalmarson, S. Goldstein, B. Fagerberg et al., "Effect of metoprolol CR/XL in chronic heart failure: metoprolol CR/XL Randomised Intervention Trial in Congestive Heart Failure (MERIT-HF)," Lancet, vol. 353, no. 9169, pp. 2001-2007, 1999.

[33] H. J. Dargie and P. Lechat, "The Cardiac Insufficiency Bisoprolol Study II (CIBIS-II): a randomised trial,” Lancet, vol. 353, no. 9146, pp. 9-13, 1999.

[34] B. Pitt, F. Zannad, W. J. Remme, R. Cody, A. Castaigne, and A. Perez, "The effect of spironolactone on morbidity and mortality in patients with severe heart failure. Randomized Aldactone Evaluation Study Investigators," The New England Journal of Medicine, vol. 341, no. 10, pp. 709-717, 1999.

[35] J. He, P. K. Whelton, L. J. Appel, J. Charleston, and M. J. Klag, "Long-term effects of weight loss and dietary sodium reduction on incidence of hypertension," Hypertension, vol. 35, no. 2, pp. 544-549, 2000.

[36] U.S. Department of Agriculture and U.S. Department of Health and Human Services, Dietary Guidelines for Americans, 2010, U.S. Government Printing Office, Washington, DC, USA, 7th edition, 2011.

[37] S. K. Gao, A. L. Fitzpatrick, B. Psaty et al., "Suboptimal nutritional intake for hypertension control in 4 ethnic groups," Archives of Internal Medicine, vol. 169, no. 7, pp. 702-707, 2009.

[38] F. M. Sacks, L. P. Svetkey, W. M. Vollmer et al., "Effects on blood pressure of reduced dietary sodium and the dietary approaches to stop hypertension (dash) diet," New England Journal of Medicine, vol. 344, no. 1, pp. 3-10, 2001.

[39] N. R. Cook, J. A. Cutler, E. Obarzanek et al., "Long term effects of dietary sodium reduction on cardiovascular disease outcomes: observational follow-up of the trials of hypertension prevention (TOHP)," British Medical Journal, vol. 334, no. 7599, pp. 885-888, 2007.

[40] L. J. Appel, "Effects of comprehensive lifestyle modification on blood pressure control: main results of the PREMIER clinical trial," Journal of the American Medical Association, vol. 289, no. 16, pp. 2083-2093, 2003.

[41] G. Specchia, S. De Servi, A. Scirè et al., "Interaction between exercise training and ejection fraction in predicting prognosis after a first myocardial infarction," Circulation, vol. 94, no. 5, pp. 978-982, 1996.

[42] S. P. Whelton, A. Chin, X. Xin, and J. He, "Effect of aerobic exercise on blood pressure: a meta-analysis of randomized, controlled trials," Annals of Internal Medicine, vol. 136, no. 7, pp. 493-503, 2002. 
[43] M. Scisney-Matlock, H. B. Bosworth, J. N. Giger et al., "Strategies for implementing and sustaining therapeutic lifestyle changes as part of hypertension management in African Americans," Postgraduate Medicine, vol. 121, no. 3, pp. 147159, 2009.

[44] C. J. Murrock and F. A. Gary, "A culturally-specific dance intervention to increase functional capacity in African American women," Journal of Cultural Diversity, vol. 15, no. 4, pp. 168 173, 2008.

[45] National Center for Health Statistics. National Health and Nutrition Examination Survey 2005-2006, http://www.cdc .gov/nchs/about/major/nhanes/nhanes2005-2006/nhanes05_ 06.htm.

[46] J. E. Mitchell, K. C. Ferdinand, K. E. Watson et al., "Treatment of heart failure in African Americans-a call to action," Journal of the National Medical Association, vol. 103, no. 2, pp. 86-98, 2011.

[47] A. L. Taylor, S. Ziesche, C. Yancy et al., "Combination of isosorbide dinitrate and hydralazine in blacks with heart failure," New England Journal of Medicine, vol. 351, no. 20, pp. 2049-2141, 2004.

[48] B. M. Psaty, N. L. Smith, D. S. Siscovick et al., "Health outcomes associated with antihypertensive therapies used as first-line agents: a systematic review and meta-analysis," Journal of the American Medical Association, vol. 277, no. 9, pp. 739-745, 1997.

[49] C. D. Furberg, J. T. Wright, B. R. Davis et al., "Major outcomes in high-risk hypertensive patients randomized to angiotensinconverting enzyme inhibitor or calcium channel blocker vs diuretic: the antihypertensive and lipid-lowering treatment to prevent heart attack trial (ALLHAT)," Journal of the American Medical Association, vol. 288, no. 23, pp. 2981-2997, 2002.

[50] F. H. Messerli, H. Makani, A. Benjo, J. Romero, C. Alviar, and S. Bangalore, "Antihypertensive efficacy of hydrochlorothiazide as evaluated by ambulatory blood pressure monitoring: a meta-analysis of randomized trials," Journal of the American College of Cardiology, vol. 57, no. 5, pp. 590-600, 2011.

[51] J. McMurray, J. Östergren, M. Pfeffer et al., "Clinical features and contemporary management of patients with low and preserved ejection fraction heart failure: baseline characteristics of patients in the Candesartan in Heart failure-assessment of Reduction in Mortality and morbidity (CHARM) programme," European Journal of Heart Failure, vol. 5, no. 3, pp. 261-270, 2003.

[52] L. H. Lindholm, B. Carlberg, and O. Samuelsson, "Should $\beta$ blockers remain first choice in the treatment of primary hypertension? A meta-analysis," Lancet, vol. 366, no. 9496, pp. 1545-1553, 2005.

[53] B. Pitt, W. Remme, F. Zannad et al., "Eplerenone, a selective aldosterone blocker, in patients with left ventricular dysfunction after myocardial infarction," New England Journal of Medicine, vol. 348, no. 14, pp. 1309-1321, 2003.

[54] H. S. Loeb, G. Johnson, A. Henrick et al., "Effect of enalapril, hydralazine plus isosorbide dinitrate, and prazosin on hospitalization in patients with chronic congestive heart failure," Circulation, vol. 87, no. 6, supplement 1, pp. VI78-VI87, 1993.

[55] D. M. McNamara, S. W. Tam, M. L. Sabolinski et al., "Aldosterone synthase promoter polymorphism predicts outcome in African Americans with heart failure. Results from the AHeFT trial," Journal of the American College of Cardiology, vol. 48, no. 6, pp. 1277-1282, 2006.
[56] J. M. Flack, D. A. Sica, G. Bakris et al., "Management of high blood pressure in blacks: an update of the International Society on Hypertension in Blacks consensus statement," Hypertension, vol. 56, no. 5, pp. 780-800, 2010.

[57] K. C. Ferdinand and A. M. Armani, "The management of hypertension in African Americans," Critical Pathways in Cardiology, vol. 6, no. 2, pp. 67-71, 2007.

[58] J. S. Floras and T. D. Bradley, "Treating obstructive sleep apnea: is there more to the story than 2 millimeters of mercury?" Hypertension, vol. 50, no. 2, pp. 289-291, 2007.

[59] E. C. Fletcher, "The relationship between systemic hypertension and obstructive sleep apnea: facts and theory," American Journal of Medicine, vol. 98, no. 2, pp. 118-128, 1995.

[60] K. Ferrier, A. Campbell, B. Yee et al., "Sleep-disordered breathing occurs frequently in stable outpatients with congestive heart failure," Chest, vol. 128, no. 4, pp. 2116-2122, 2005.

[61] S. Redline, P. V. Tishler, M. G. Hans, T. D. Tosteson, K. P. Strohl, and K. Spry, "Racial differences in sleep-disordered breathing in African-Americans and Caucasians," American Journal of Respiratory and Critical Care Medicine, vol. 155, no. 1, pp. 186-192, 1997.

[62] T. Young, P. Peppard, M. Palta et al., "Population-based study of sleep-disordered breathing as a risk factor for hypertension," Archives of Internal Medicine, vol. 157, no. 15, pp. 1746-1752, 1997.

[63] J. Godoy, P. Mellado, J. Tapia, and J. Santín, "Obstructive Sleep Apnea as an independent stroke risk factor: possible mechanisms," Current Molecular Medicine, vol. 9, no. 2, pp. 203-209, 2009.

[64] O. Friedman and A. G. Logan, "The price of obstructive sleep apnea-hypopnea: hypertension and other ill effects," American Journal of Hypertension, vol. 22, no. 5, pp. 474-483, 2009.

[65] P. Lavie, P. Herer, and V. Hoffstein, "Obstructive sleep apnoea syndrome as a risk factor for hypertension: population study," British Medical Journal, vol. 320, no. 7233, pp. 479-482, 2000.

[66] P. E. Peppard, T. Young, M. Palta, and J. Skatrud, "Prospective study of the association between sleep-disordered breathing and hypertension," New England Journal of Medicine, vol. 342, no. 19, pp. 1378-1384, 2000.

[67] E. Shahar, C. W. Whitney, S. Redline et al., "Sleep-disordered breathing and cardiovascular disease: cross-sectional results of the sleep heart health study," American Journal of Respiratory and Critical Care Medicine, vol. 163, no. 1, pp. 19-25, 2001.

[68] T. D. Bradley and J. S. Floras, "Obstructive sleep apnoea and its cardiovascular consequences," The Lancet, vol. 373, no. 9657, pp. 82-93, 2009.

[69] M. Alchanatis, G. Paradellis, H. Pini, G. Tourkohoriti, and J. Jordanoglou, "Left ventricular function in patients with obstructive sleep apnoea syndrome before and after treatment with nasal continuous positive airway pressure," Respiration, vol. 67, no. 4, pp. 367-371, 2000.

[70] J.-P. Laaban, S. Pascal-Sebaoun, E. Bloch, E. Orvoën-Frija, J.M. Oppert, and G. Huchon, "Left ventricular systolic dysfunction in patients with obstructive sleep apnea syndrome," Chest, vol. 122, no. 4, pp. 1133-1138, 2002.

[71] M. A. Arias, F. García-Río, A. Alonso-Fernández, O. Mediano, I. Martínez, and J. Villamor, "Obstructive sleep apnea syndrome affects left ventricular diastolic function: effects of nasal continuous positive airway pressure in men," Circulation, vol. 112, no. 3, pp. 375-383, 2005.

[72] J. Chan, J. Sanderson, W. Chan et al., "Prevalence of sleepdisordered breathing in diastolic heart failure," Chest, vol. 111, no. 6, pp. 1488-1493, 1997. 
[73] R. Hyer, Obstructive Sleep Apnea Linked to Vulnerable Vessel Plaque on CT. Internal Medicine News, Elsevier, 2011.

[74] D. R. Mansfield, N. C. Gollogly, D. M. Kaye, M. Richardson, P. Bergin, and M. T. Naughton, "Controlled trial of continuous positive airway pressure in obstructive sleep apnea and heart failure," American Journal of Respiratory and Critical Care Medicine, vol. 169, no. 3, pp. 361-366, 2004.

[75] T. L. Giles, T. J. Lasserson, B. J. Smith, J. White, J. Wright, and C. J. Cates, "Continuous positive airways pressure for obstructive sleep apnoea in adults (Review)," Cochrane Database of Systematic Reviews, no. 3, Article ID CD001106, 2006.

[76] U. J. Magalang, K. Richards, B. McCarthy et al., "Continuous positive airway pressure therapy reduces right ventricular volume in patients with obstructive sleep apnea: a cardiovascular magnetic resonance study," Journal of Clinical Sleep Medicine, vol. 5, no. 2, pp. 110-114, 2009.

[77] Y. Kaneko, J. S. Floras, K. Usui et al., "Cardiovascular effects of continuous positive airway pressure in patients with heart failure and obstructive sleep apnea," New England Journal of Medicine, vol. 348, no. 13, pp. 1233-1241, 2003.

[78] J. C. T. Pepperell, S. Ramdassingh-Dow, N. Crosthwaite et al., "Ambulatory blood pressure after therapeutic and subtherapeutic nasal continuous positive airway pressure for obstructive sleep apnoea: a randomised parallel trial," Lancet, vol. 359, no. 9302, pp. 204-210, 2002.

[79] J. E. Dimsdale, J. S. Loredo, and J. Profant, "Effect of continuous positive airway pressure on blood pressure: a placebo trial," Hypertension, vol. 35, no. 1 I, pp. 144-147, 2000.

[80] J. F. Faccenda, T. W. Mackay, N. A. Boon, and N. J. Douglas, "Randomized placebo-controlled trial of continuous positive airway pressure on blood pressure in the sleep apnea-hypopnea syndrome," American Journal of Respiratory and Critical Care Medicine, vol. 163, no. 2, pp. 344-348, 2001.

[81] H. F. Becker, A. Jerrentrup, T. Ploch et al., "Effect of nasal continuous positive airway pressure treatment on blood pressure in patients with obstructive sleep apnea," Circulation, vol. 107, no. 1, pp. 68-73, 2003.

[82] F. Campos-Rodriguez, A. Grilo-Reina, J. Perez-Ronchel et al., "Effect of continuous positive airway pressure on ambulatory BP in patients with sleep apnea and hypertension: a placebocontrolled trial," Chest, vol. 129, no. 6, pp. 1459-1467, 2006.

[83] F. Campos-Rodriguez, J. Perez-Ronchel, A. Grilo-Reina, J. Lima-Alvarez, M. A. Benitez, and C. Almeida-Gonzalez, "Long-term effect of continuous positive airway pressure on BP in patients with hypertension and sleep apnea," Chest, vol. 132, no. 6, pp. 1847-1852, 2007.

[84] J. Durán-Cantolla, F. Aizpuru, J. M. Montserrat et al., "Continuous positive airway pressure as treatment for systemic hypertension in people with obstructive sleep apnoea: randomised controlled trial," British Medical Journal, vol. 341, p. c5991, 2010.

[85] C. J. Egea, F. Aizpuru, J. A. Pinto et al., "Cardiac function after CPAP therapy in patients with chronic heart failure and sleep apnea: a multicenter study," Sleep Medicine, vol. 9, no. 6, pp. 660-666, 2008.

[86] D. M. Becker, M. B. Tuggle, and M. F. Prentice, "Building a gateway to promote cardiovascular health research in AfricanAmerican communities: lessons and findings from the field," American Journal of the Medical Sciences, vol. 322, no. 5, pp. 288-293, 2001.
[87] K. F. Adams, J. Lindenfeld, J. M. O. Arnold et al., "Executive summary: HFSA 2006 comprehensive heart failure practice guideline," Journal of Cardiac Failure, vol. 12, no. 1, pp. 10-38, 2006.

[88] D. Levy, S. Kenchaiah, M. G. Larson et al., "Long-term trends in the incidence of and survival with heart failure," Revista Portuguesa de Cardiologia, vol. 21, no. 11, pp. 1377-1378, 2002. 


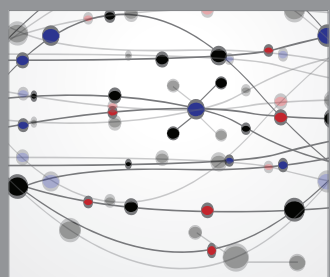

The Scientific World Journal
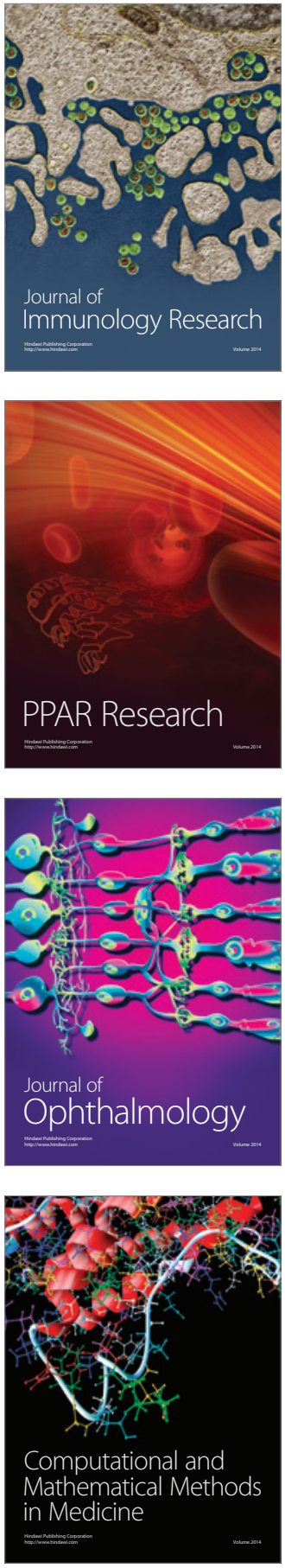

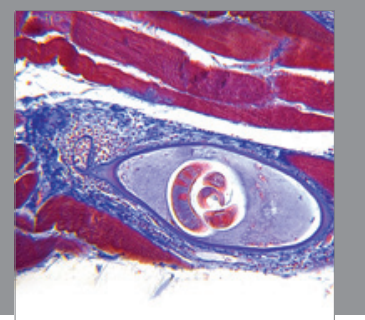

Gastroenterology

Research and Practice
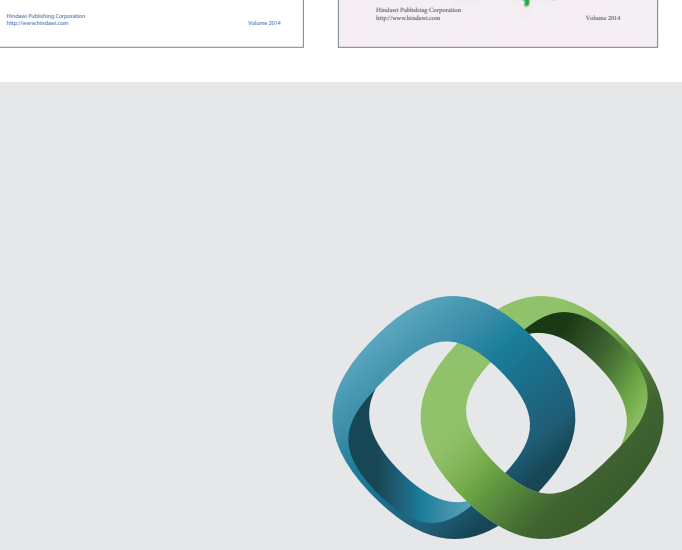

\section{Hindawi}

Submit your manuscripts at

http://www.hindawi.com
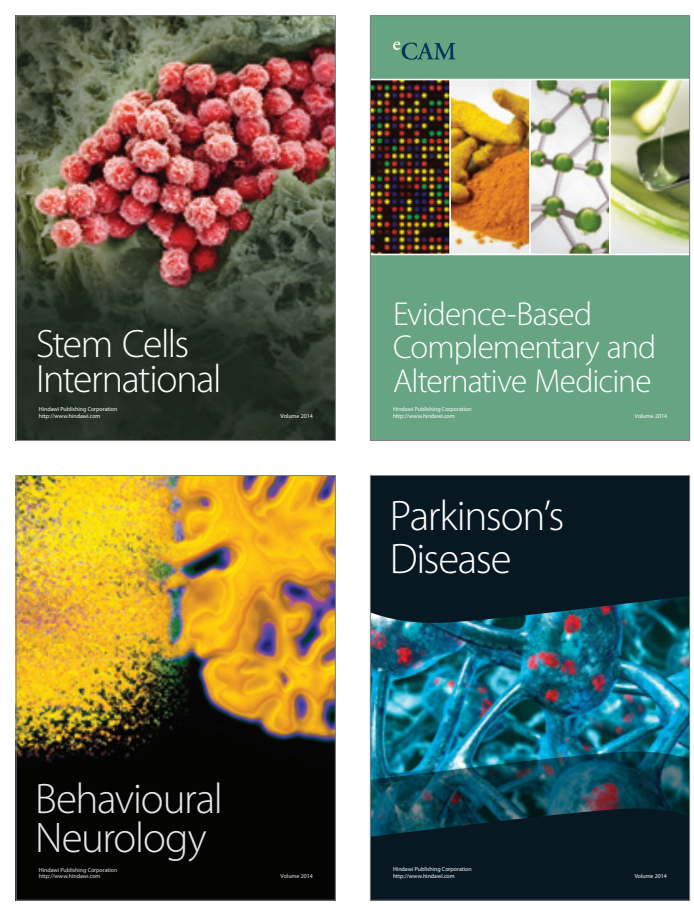

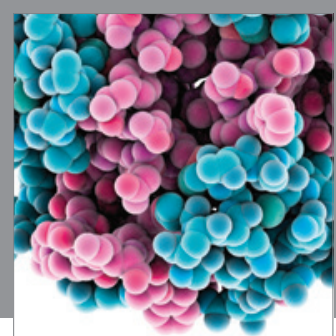

Journal of
Diabetes Research

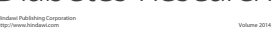

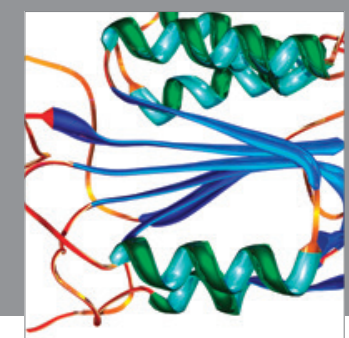

Disease Markers
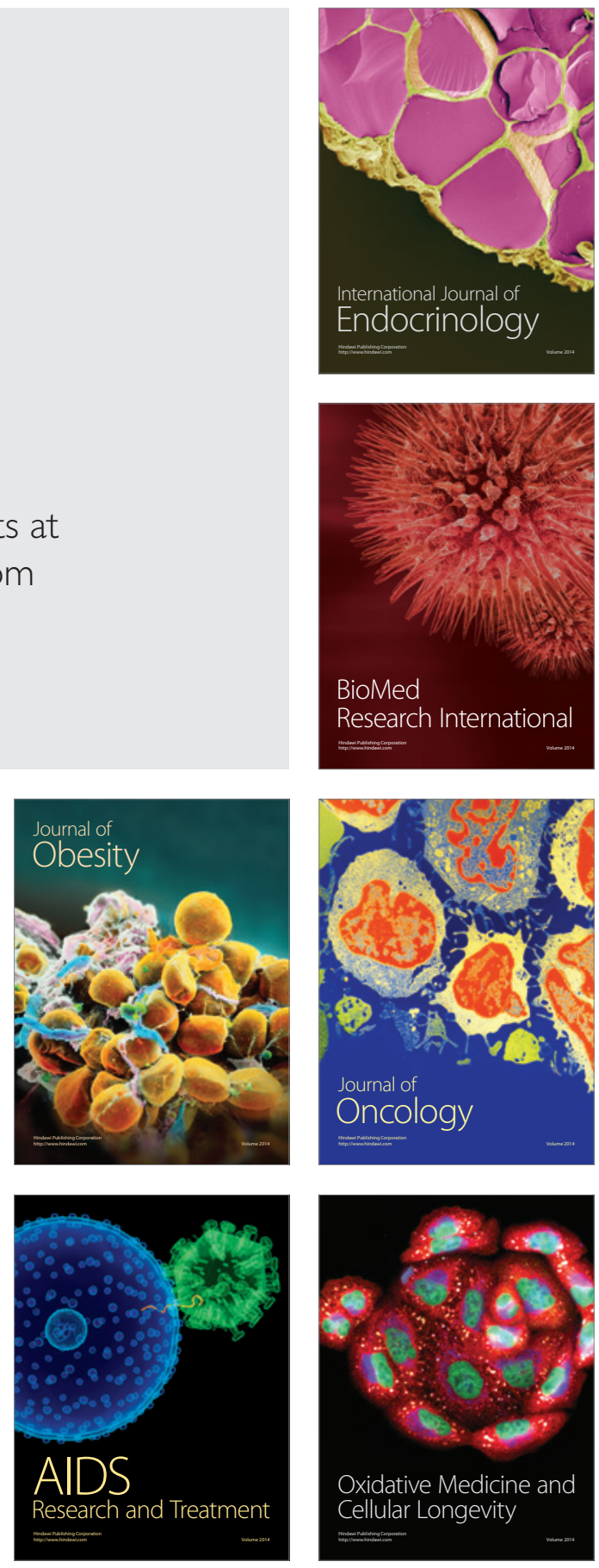